\title{
Aplicação da Tríplice Contingência da Análise Comportamental na Gamificação do Módulo de Ensino e Aprendizagem da Lógica Proposicional
}

\author{
Fernanda Pereira Gomes ${ }^{1}$, Parcilene Fernandes de Brito ${ }^{1}$, Heloíse Acco Tives Leão ${ }^{1}$, \\ Fabiano Fagundes ${ }^{1}$, Edna Dias Canedo² \\ ${ }^{1}$ Departamento de Sistemas e Computação \\ Centro Universitário Luterano de Palmas (CEULP/ULBRA) - Palmas, TO - Brazil \\ ${ }^{2}$ Departamento de Ciência da Computação \\ Universidade de Brasília (UNB) - Brasília, DF - Brazil \\ \{fernandagomes769, parcilene, heloise.acco, thilfa\}@gmail.com, \\ ednacanedo@unb.br
}

\begin{abstract}
In the educational context, it has been developed gamified systems in order to get better levels of engagement of the contents approached in the disciplines. Therefore, it is important to understand the behavior of the users in these environments, especially in the definition of elements that stimulate learning. In this sense, this article aims to present the procedures performed for the presents the gamification process of the truth table module according to the concepts of the Three-Term Contingency of Behavior Analysis. This module is included in a gamified platform called Logic Live, which assists academics and teachers in the process of teaching and learning the Logic discipline. The results obtained are similar to the process steps: "Antecedent Variables", "User Behavior" and "Consequent Variables".
\end{abstract}

Resumo. No contexto educacional, tem sido desenvolvido sistemas gamificados com o intuito de obter melhores níveis de engajamento dos conteúdos abordados nas disciplinas. Para tanto, é importante o entendimento do comportamento do usuário nesses ambientes, especialmente, para definição de elementos que estimulem a aprendizagem. Nesse sentido, este trabalho apresenta o processo de gamificação do módulo de tabelaverdade de acordo com os conceitos da Tríplice Contingência da Análise Comportamental. Este módulo está inserido em uma plataforma gamificada, intitulada Logic Live, que auxilia acadêmicos e professores no processo de ensino e aprendizagem da disciplina de Lógica. Os resultados obtidos correspondem à implementação do módulo gamificado considerando as três etapas do processo: "Variáveis Antecedentes", "Comportamento do Usuário" $e$ "Variáveis Consequentes".

\section{Introdução}

Nos cursos da área da computação, a disciplina de Lógica geralmente compreende conteúdos como raciocínio lógico, formalização de sentenças, entendimentos dos operadores lógicos por meio de tabelas verdade, verificação da validade de fórmulas, entre outros conhecimentos que são necessários para fundamentar "a sólida formação em Ciência da Computação e Matemática” apontada nas Diretrizes Curriculares Nacionais para os cursos de graduação na 
VIII Congresso Brasileiro de Informática na Educação (CBIE 2019)

Anais do XXX Simpósio Brasileiro de Informática na Educação (SBIE 2019)

área da Computação [MEC 2019]. A Lógica Proposicional, parte do conteúdo apresentado na disciplina de Lógica, segundo Bedregal e Acióly (2007), fornece embasamento para a análise de proposições/argumentos que podem ser verdadeiros ou falsos visando obter uma prova de que determinada conclusão é verdadeira em um determinado contexto. A partir de pesquisas realizadas em Medeiros e Haydu (2015), Zanin et al. (2018) e Ribeiro et al. (2018), verificou-se que a aplicação de elementos de design de jogos no contexto educacional pode estimular os comportamentos dos estudantes, proporcionando um maior engajamento destes em sala de aula, tornando as atividades mais divertidas e com melhores resultados. Referente ao conceito de comportamento, sabe-se que este não se traduz apenas em uma resposta do organismo a um estímulo antecedente, mas ocorre principalmente em função das consequências que o comportamento produz, que são mudanças ambientais percebidas pelo organismo como contingentes à sua ação [SKINNER, 1982]. Conforme Werbach e Hunter (2012), para o sucesso de um projeto de gamificação é essencial estabelecer uma relação entre os elementos de jogos utilizados.

Em consonância com essa afirmação, segundo Skinner (1982), os jogos funcionam como "programadores" de contingências, que para a Análise Comportamental consistem na relação estabelecida entre os aspectos das situações que antecedem o comportamento do organismo, as características do comportamento, e aspectos do ambiente que sucedem tal comportamento. Para entender tal relação, Skinner (1974) desenvolveu a unidade da análise comportamental intitulada Tríplice Contingência, que estuda os comportamentos específicos dos organismos produzidos por meio de sua história de aprendizagem. Sabendo disso, este artigo apresenta o uso dos conceitos da Tríplice Contingência na gamificação do módulo de tabela verdade desenvolvido na plataforma gamificada Logic Live. Esta plataforma visa auxiliar alunos e professores no processo de ensino e aprendizagem de Lógica, desde o processo de formalização de argumentos até na verificação da validade das fórmulas. $\mathrm{O}$ módulo implementado neste trabalho aborda os conceitos referentes à Lógica Proposicional, métodos de prova e verificações de formas de argumento a partir do uso de tabelas verdade. Um conjunto de contingências foram definidas para guiar o processo de design da gamificação do módulo. Nesse sentido, foram seguidas as etapas: identificação das Variáveis Antecedentes, do Comportamento do Usuário e das Variáveis Consequentes; sendo cada uma delas baseadas nos aspectos que compreendem a Tríplice.

\section{Tríplice Contingência da Análise Comportamental}

Comportamento, segundo Skinner (1982), é a parte do funcionamento do organismo responsável pela sua ação sobre, ou interação com, o mundo externo, ou também, a relação essencial e contínua entre o ambiente e as ações de um organismo. A Análise do Comportamento (AC) é um campo de pesquisa fundado pelo psicólogo Skinner, que caracterizou os comportamentos em três tipologias: filogenéticos, ontogenéticos e culturais. Conforme Medeiros e Haydu (2015), os comportamentos filogenéticos são reflexos que não necessitam de um contexto de aprendizado para acontecer, pois são obtidos hereditariamente; já os ontogenéticos são apresentados ao longo da vida, em função de um contexto de aprendizado, e os culturais levam em conta as particularidades da cultura em que o indivíduo está inserido. 
VIII Congresso Brasileiro de Informática na Educação (CBIE 2019)

Anais do XXX Simpósio Brasileiro de Informática na Educação (SBIE 2019)

Skinner (1982) expõe que parte dos comportamentos ontogenéticos acontece basicamente em função de consequências que, segundo ele, são mudanças ambientais percebidas pelo organismo como contingentes. Segundo Prette (2011), ao observar os comportamentos de indivíduos, pesquisadores constataram relações entre as respostas dos organismos e suas consequências. Com isso, percebeu-se que o comportamento corresponde à relação entre estímulos antecedentes e consequentes a uma resposta, e a essa relação dá-se o nome de Tríplice Contingência. Conforme Skinner (1974), a contingência é o modo de representar como determinados comportamentos surgem e se mantêm ao longo do tempo. A Análise Comportamental utiliza a Tríplice Contingência para entender a relação na qual um estímulo consequente a uma classe de respostas altera a probabilidade de emissão das mesmas respostas no futuro em uma situação semelhante. Tal relação pode ser representada graficamente, como mostra a Figura 1 a seguir.

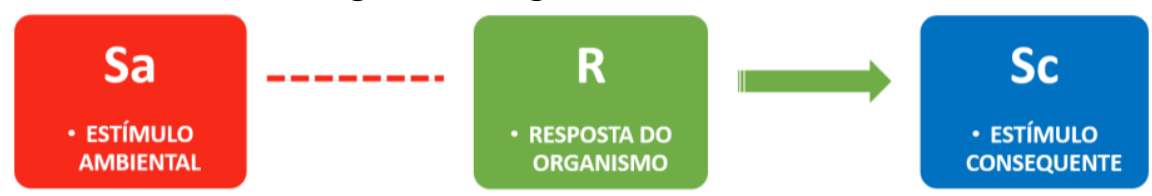

Figura 1. Representação da Tríplice Contingência Fonte: Adaptado de Skinner (1974)

O estímulo ambiental $(\mathrm{Sa})$ representa os estímulos discriminativos necessários para que o indivíduo possa emitir um comportamento; a resposta $(\mathrm{R})$ representa o comportamento do indivíduo em um determinado contexto, mas não significa que essa resposta necessariamente ocorra, e sim que há uma probabilidade disso vir a acontecer; e o estímulo consequente (Sc), produzido em função de R, é utilizado para reforçar, diminuir ou extinguir o comportamento, a seta indica que necessariamente toda resposta produz uma consequência. De modo geral, deve-se entender que dado um estímulo, uma resposta poderá ocorrer e essa irá gerar uma consequência que retroage na resposta de forma que a chance de emissão de uma nova resposta semelhante seja maior ou menor, conforme o caso [PRETTE, 2011]. Nesse sentido, Menezes et al. (2014) apontam que os estímulos oferecidos pelo ambiente suscitam respostas que, por sua vez, serão recompensadas ou punidas, reforçando ou reduzindo determinados comportamentos. Assim, o indivíduo aprende a repetir certos atos, enquanto "desaprende" outros, moldando, aos poucos, um conjunto de comportamentos que, somados, constituem uma espécie de repertório da sua conduta frente ao mundo.

\section{Gamificação na Educação}

Trabalhos que utilizam gamificação na educação geralmente buscam desenvolver propostas que contemplem aspectos de ludicidade, mecanismos de jogos, com uma abordagem desafiadora a fim de aumentar o engajamento dos alunos nos processos educacionais, por meio de um ambiente motivador e divertido [Rice, 2012; Kiesler et al., 2011; Klock et al., 2015]. Considerando este cenário, foram identificados dois trabalhos relacionados. Em Leon et al. (2011), é apresentado o programa intitulado Headsprout (ou Headsprout Early Reading) que ensina fonética, consciência fonêmica, vocabulário e compreensão de textos sem a supervisão de um professor, utilizando sequências de aprendizagem expressas em um contexto de jogo. Para o design da gamificação do programa Headsprout foi seguido um procedimento dividido em seis etapas: "Análise de conteúdo", "Objetivos instrucionais", 
"Critérios de testes", "Repertório de entrada", "Sequência instrucional" e "Dados de desempenho". Segundo os autores, ao seguir tais etapas foi possível planejar os conteúdos que seriam apresentados, definir quais estratégias seguir para ensinar as crianças a compreender os textos lidos e também os elementos de jogos para compor o programa de forma a tornar o aprendizado mais divertido e motivar as crianças a continuar melhorando suas habilidades de leitura [LEON et al., 2011].

Já no trabalho de Klock et al. (2016), é apresentada a gamificação de um sistema educacional usado por acadêmicos de uma instituição de ensino superior para apoiar o processo a aprendizagem da disciplina de Algoritmos de Programação, que segundo os autores possui um alto índice de reprovações [KLOCK et al., 2016]. Para auxiliar no processo de design da gamificação, os autores desenvolveram um Framework, intitulado como 5W2H, que possui sete dimensões ordenadas da seguinte forma: “Quem?”, “O que?", "Por quê?”, "Quando?”, “Como?”, “Onde?” e "Quanto?”. Cada dimensão do Framework possui um objetivo específico, descreve aspectos a serem analisados e identifica os atores envolvidos. Neste trabalho, a gamificação do sistema foi definida para engajar comportamentalmente os usuários por meio de atividades que estimulem e mantenham a interação, comunicação e desempenho dos usuários [KLOCK et al., 2016].

\section{Tríplice Contingência na Gamificação do Módulo de Tabela Verdade}

Para a gamificação do módulo de tabela verdade, os procedimentos realizados foram baseados nos elementos que compõem a representação da Tríplice Contingência da Análise Comportamental [Skinner 1958, Skinner 1974 e Foxall 2010]. Como mostra a Figura 2, os procedimentos foram divididos em três etapas: a primeira etapa, baseada no estímulo ambiental (Sa) da Tríplice Contingência (Figura 1) intitulada Variáveis Antecedentes, objetivou a definição inicial do domínio do módulo e da estrutura capaz de estimular os comportamentos dos usuários. Na subetapa "Cenário do comportamento do usuário" foi identificado inicialmente que o módulo de tabela verdade pertence ao contexto educacional, pois está integrado à disciplina de Lógica de uma instituição de ensino. O uso do módulo está inserido no plano de ensino da disciplina, como uma forma diferenciada de metodologia e, também, como uma atividade avaliativa de aprendizagem.
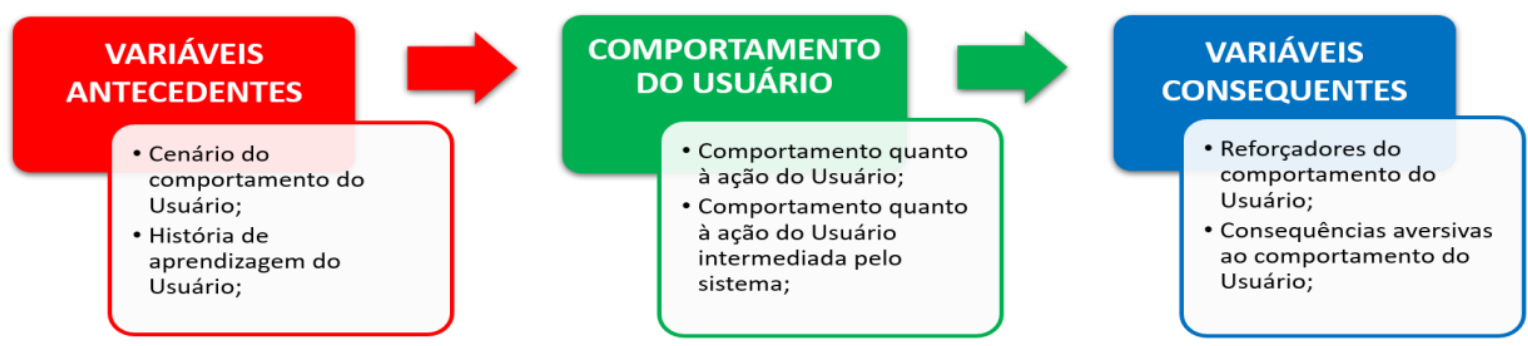

Figura 2. Representação dos procedimentos realizados baseados na Tríplice Contingência Fonte: Elaborado pela própria autora

Posteriormente, foi realizada a verificação dos possíveis cenários do módulo e o desenvolvimento do projeto inicial da estrutura capaz de suportar a gamificação. A partir de reuniões realizadas com a especialista do domínio, que neste caso é a professora da disciplina, a idealizadora da plataforma Logic Live e uma das autoras do artigo, foi definido que a estrutura projetada seria composta por três módulos: "Módulo 1 - Estudo dos Conceitos da 
VIII Congresso Brasileiro de Informática na Educação (CBIE 2019)

Anais do XXX Simpósio Brasileiro de Informática na Educação (SBIE 2019)

Lógica Proposicional", "Módulo 2 - Criação de tabelas verdades e identificação de fórmulas", "Módulo 3 - Verificação da validade de formas de argumento". O Módulo 1 apresenta os conceitos básicos abordados na disciplina, de modo que o usuário efetue inicialmente o estudo desses conceitos antes de realizar qualquer atividade. Além disso, é constituído de dois níveis, o Nível 1 intitulado "Estudo dos operadores e da semântica da Lógica Proposicional", definido para apresentar conceitos da Lógica Proposicional e o Nível 2, intitulado "Estudo do método da Tabela Verdade", para apresentar conceitos relacionados ao método da Tabela Verdade, bem como exemplificações de sua utilização para a validade de formas de argumentos. Conforme sugestão da especialista do domínio, os Módulos 2 e 3 foram subdivididos em três níveis cada para constituírem um conjunto de exercícios, com graus diferentes de dificuldade, que abrangem os conteúdo apresentados no Módulo 1. Cada nível é composto por cinco exercícios, elaborados de modo que cada exercício possua uma fórmula da Lógica Proposicional diferente para ser estudada.

Após os cenários estarem desenvolvidos, na subetapa "História de aprendizagem do usuário", foram identificados os tipos de usuários do módulo de tabela verdade, que serão acadêmicos matriculados na disciplina de Lógica. Ainda na primeira etapa, foram definidas as variáveis de controle para indicar situações específicas do comportamento do usuário no módulo, são elas: controle da quantidade de solicitações de ajuda em cada Nível/Módulo; controle da quantidade de erros (nas perguntas dos exercícios em cada nível $/ \mathrm{módulo} \mathrm{e} \mathrm{na}$ criação das tabelas verdade em cada Nível/Módulo); e controle do tempo de resolução dos exercícios. Na segunda etapa intitulada Comportamento do Usuário (Figura 2), baseada na resposta do organismo $(\mathrm{R})$ da Tríplice Contingência, foram identificados os possíveis comportamentos dos usuários a serem estimulados pelas variáveis antecedentes (etapa anterior). Nesse sentido, na subetapa “Comportamento Quanto à Ação do Usuário”, foi criada uma lista contendo os possíveis comportamentos identificados em relação ao uso dos elementos que o módulo apresentará, e estes foram:

- Estudar as temáticas do Módulo 1: Marcar como concluído o estudo dos conceitos apresentados; Desistir do estudo dos níveis por um tempo ou por mais de um mês (corresponderá a abandono);

- Resolver os exercícios dos Módulos 2, 3: Marcar como concluído a resolução dos exercícios; Solicitar ajuda durante a resolução dos exercícios; Desistir da resolução de exercícios por um tempo ou por mais de um mês;

- Caso ocorra erro na resolução de exercícios (por parte do usuário): Refazer o exercício; Desistir por um tempo ou por mais de um mês.

Na subetapa intitulada "Comportamento quanto à ação do usuário intermediada pelo sistema", foram identificados alguns comportamentos do usuário a serem intermediados pelo módulo de tabela verdade. Em relação ao comportamento de resolução dos exercícios, têmse que o tempo gasto para a resolução será calculado via sistema (com o apoio da variável de controle já definida) e apresentado aos usuários, de modo a estimulá-los a resolver os exercícios com tempos cada vez menores, sabendo que para isso ocorrer, deverão ter maior conhecimento dos conteúdos de estudo apresentados no Módulo 1. Na terceira etapa, intitulada Variáveis Consequentes (Figura 2) baseada no estímulo consequente (Sc) da Tríplice Contingência, foi realizada a definição do projeto da gamificação do módulo, capaz de estimular os comportamentos identificados (etapa anterior) do público-alvo nos cenários definidos na primeira etapa. Com isso na subetapa "Reforçadores do comportamento do 
VIII Congresso Brasileiro de Informática na Educação (CBIE 2019)

Anais do XXX Simpósio Brasileiro de Informática na Educação (SBIE 2019)

usuário”, ocorreu a definição das dinâmicas, mecânicas e componentes de jogos para compor o módulo. Analisando os comportamentos identificados, dentre as dinâmicas para a gamificação existentes, foram definidas: dinâmica de Progressão (para estimular o engajamento do usuário nas atividades de estudo) e dinâmica de Restrição (para motivar atingir os objetivos propostos no módulo). Quanto às mecânicas, foi definido que os usuários receberão Feedback sobre o seu progresso nas atividades realizadas no módulo, para isso, serão utilizados elementos da interface como ícones e barras de progresso. Para o fortalecimento da dinâmica de restrições, também foi considerada a mecânica de recompensas.

Sobre os componentes de jogos, foram definidos avatares como forma de representar os usuários no módulo, para as recompensas definiu-se os emblemas, os pontos e interligados com a dinâmica de progressão e a mecânica de Feedback definiu-se os componentes de níveis e tabela de classificação, que exibirá o ranking dos cinco primeiros usuários que mais pontuaram no módulo de tabela verdade. Além disso, foram estabelecidos os reforçadores de comportamento do usuário conforme a dificuldade de realização e a importância do comportamento para o processo de aprendizagem no módulo. Nesse sentido, dentre os reforços definidos o usuário obterá, por exemplo, 40 pontos e um emblema personalizado ao concluir o estudo dos conceitos do Módulo 1, já ao finalizar um nível de exercícios com grau de dificuldade avançado obterá 100 pontos, e ao concluir os exercícios dos Módulos 2 e 3 obterá 150 pontos e um emblema. Como é desejado reforçar o processo de ensino e aprendizagem, as maiores recompensas serão atribuídas somente nas atividades que requerem maior interação do usuário. Por fim, na subetapa intitulada "Consequências aversivas ao comportamento do usuário", foram analisadas possíveis situações que possam diminuir a chance da resposta (ou do comportamento) do usuário ocorrer. Diante disso, definiu-se que a variável de controle do tempo de resolução dos exercícios irá auxiliar na percepção do comportamento de desistência do usuário. Nesse sentido, se for percebida a passagem de um longo período de tempo do usuário logado, mas sem emitir nenhuma resposta, são enviadas mensagens apresentando ajuda no conteúdo relacionado ao exercício, e até mesmo exemplos de como resolvê-lo.

\section{Apresentação do Módulo de Tabela Verdade}

Com base no projeto de gamificação realizado, o módulo de tabela verdade foi implementado. Desenvolveu-se inicialmente a Página de acesso, de recuperação de senhas e a Página para cadastro de usuários. $\mathrm{O}$ usuário cadastrado tem acesso à página inicial do módulo, como mostra a Figura 3. Nesta página foi usado o componente card para a apresentação das informações dos Módulos 1, 2 e 3 (Figura 3-A). Além da descrição do Módulo correspondente, cada card possui uma barra de progresso que indica ao usuário seu status atual no Módulo de acordo com o seu progresso nas atividades propostas. Também foi implementado na página inicial um espaço lateral de conteúdo para a apresentação das recompensas obtidas pelos usuários, como sua pontuação atual e os emblemas conquistados (Figura 3-B). Já a tabela de classificação - disposta após as informações das recompensas foi implementada para exibir o ranking dos usuários, seguida da classificação do usuário que estiver logado (Figura 3-B). Na parte superior da página (Figura 3-C), foi implementada a barra de informações, em que são apresentados dois botões, o primeiro corresponde ao botão para exibição dos emblemas que o usuário poderá conquistar no módulo, e o segundo, que 
VIII Congresso Brasileiro de Informática na Educação (CBIE 2019)

Anais do XXX Simpósio Brasileiro de Informática na Educação (SBIE 2019)

fica ao lado do nome de usuário, irá apresentar o avatar definido que ao ser clicado exibirá os seguintes links: "Configurações”, redireciona o usuário para a página de configuração de perfil; e "Sair", finaliza a sessão do usuário no módulo.

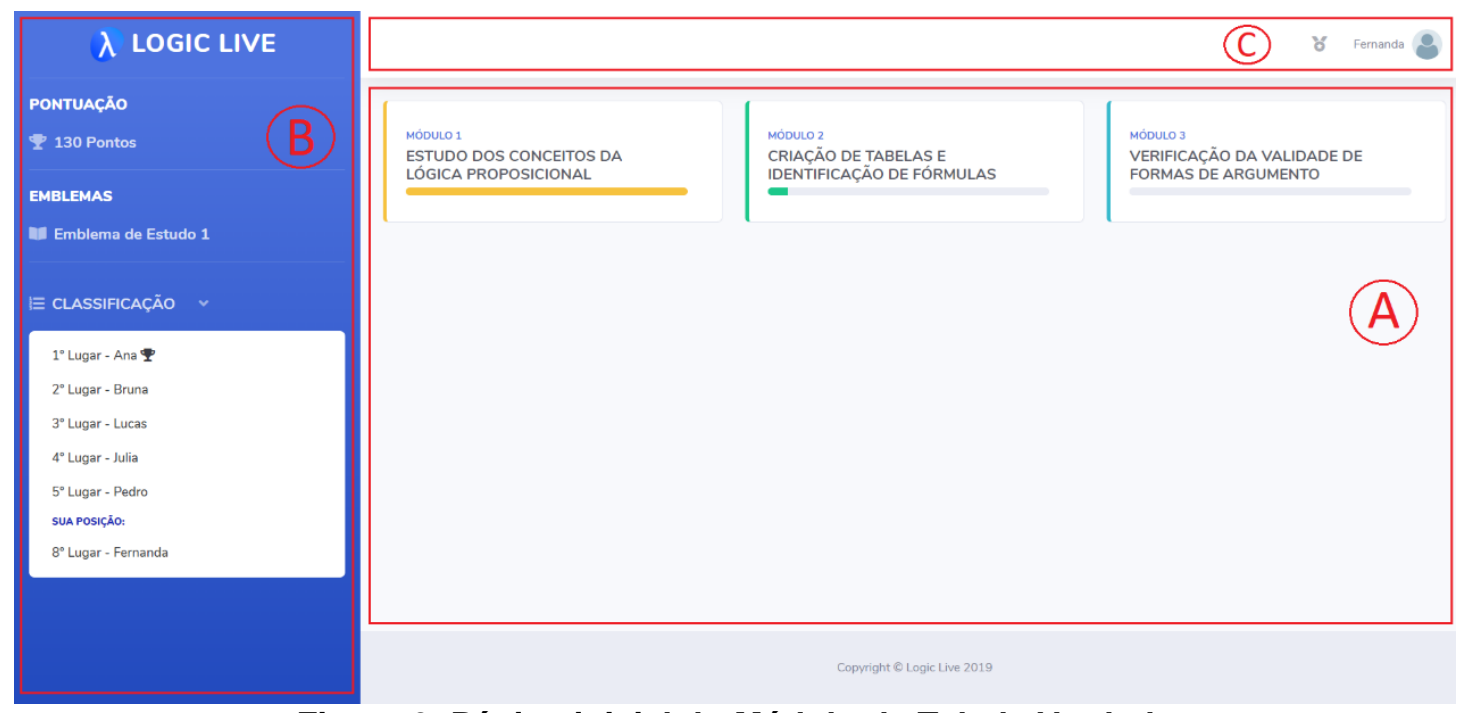

Figura 3. Página inicial do Módulo de Tabela Verdade

Fonte: Elaborado pela própria autora

Os cards foram implementados de forma que funcionem como um link para a página que exibe os exercícios do Módulo correspondente. Conforme definido na estrutura do módulo, o usuário terá que realizar primeiramente o estudo dos conceitos dispostos nos exercícios do Módulo 1. Nesse Módulo, apenas o "Exercício 1" está liberado e o próximo exercício é apresentado com um ícone de cadeado, indicando que está bloqueado para acesso. Para que o próximo exercício seja desbloqueado, no caso o "Exercício 2", o usuário terá que realizar o estudo dos conceitos apresentados na página do "Exercício 1". Nesta página são apresentados estímulos para a conclusão do estudo: a barra de conteúdo lateral exibe a recompensa que será obtida, um contador de tempo exibirá o tempo gasto no estudo, e um botão intitulado "Concluir Estudo" - exibido somente no final da página - que ao ser clicado indicará o comportamento de finalização do estudo das temáticas do exercício, e como consequência desse comportamento a atribuição da recompensa.

Após completar o Módulo 1, o usuário estará apto para iniciar os exercícios do Módulo 2, que aborda a criação de tabelas verdade. Ao clicar no link do exercício desbloqueado deste módulo o usuário será redirecionado para a página padrão de exercícios, como mostra a Figura 4, que foi desenvolvida para apresentar os exercícios dos Módulos 2 e 3. Para estimular o processo de ensino e aprendizagem os exercícios foram divididos em duas etapas, sendo a primeira delas constituída de questionamentos que fundamentam a resolução da atividade presente na segunda etapa, que consiste na construção de tabelas verdade. Na página dos exercícios têm-se inicialmente o card para exibição da fórmula da Lógica Proposicional (Figura 4-A) e em seguida os campos para inserção das respostas das perguntas. A primeira etapa do exercício (Figura 4-B) pode resultar nos seguintes comportamentos: a resposta às perguntas nos campos indicados, a solicitação de ajuda clique no botão posicionado ao lado do campo de inserção das respostas - caso apresente alguma dificuldade, a finalização da primeira etapa - clique no botão "Responder"-, ou a 
VIII Congresso Brasileiro de Informática na Educação (CBIE 2019)

Anais do XXX Simpósio Brasileiro de Informática na Educação (SBIE 2019)

desistência de resolução do exercício por um período de tempo, identificado pela variável de controle do tempo de resolução. Ao ser identificado este último comportamento, será exibida uma caixa de diálogo sugerindo que o usuário volte à resolução do exercício.

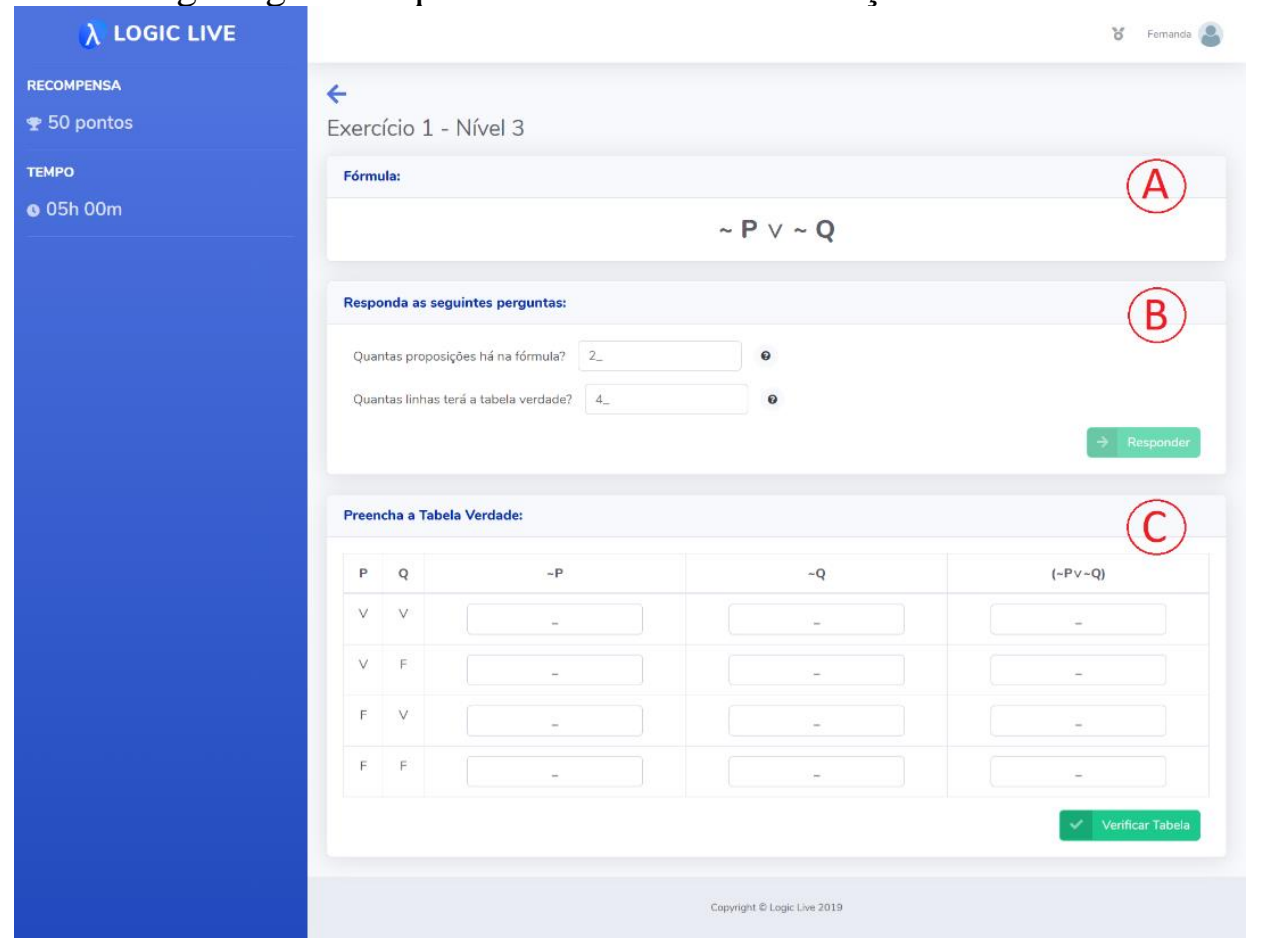

Figura 4. Página padrão para resolução dos exercícios do Módulo de Tabela Verdade Fonte: Elaborado pela própria autora

Vale ressaltar que nesta etapa a quantidade de perguntas e seus enunciados são definidos pelo(a) professor(a) da disciplina, e os conteúdos apresentados após a solicitação de ajuda são relacionados com as perguntas cadastradas no módulo. após o usuário clicar no botão intitulado "Responder" (Figura 4-B) as respostas informadas serão verificadas, caso seja identificada alguma resposta incorreta será exibida uma notificação de "Resposta Incorreta" e uma mensagem solicitando a verificação das respostas informadas. Caso estejam corretas, será apresentada uma notificação de "Resposta Correta" e a segunda etapa do exercício, que fica desabilitada até que os usuários respondam corretamente às perguntas da primeira etapa, é habilitada e apresentada na página, como mostra a Figura 4-C.

Na segunda etapa do exercício é apresentada a tabela verdade da fórmula, no entanto, apenas os valores-verdade das proposições (neste caso apresentado na Figura 4-C as proposições são P e Q) são apresentados, "V" para Verdadeiro e "F" para Falso. Como comportamentos esperados nesta etapa, têm-se: o preenchimento dos valores-verdade das subfórmulas nos demais campos em branco, a finalização da segunda etapa - clique no botão "Verificar Tabela"-, ou a desistência do preenchimento por um período de tempo. Ao finalizar a segunda etapa, caso o usuário tenha preenchido valores incorretos, será apresentada uma notificação de "Resposta Incorreta". Os usuários após visualizarem esta notificação, deverão identificar nos campos preenchidos da tabela verdade o(s) erro(s) cometido(s). Após realizarem as alterações, devem clicar novamente no botão de "Verificar Tabela" e ao ser confirmado o preenchimento correto dos valores-verdade, será apresentada 
VIII Congresso Brasileiro de Informática na Educação (CBIE 2019)

Anais do XXX Simpósio Brasileiro de Informática na Educação (SBIE 2019)

a notificação de "Resposta Correta". Com a conclusão, o próximo exercício é então liberado e os usuários poderão iniciar sua resolução. Ao finalizar os exercícios do Módulo 2, os usuários estarão aptos a iniciarem a resolução dos exercícios do Módulo 3, que trata da verificação da validade de fórmulas da Lógica Proposicional. Vale ressaltar que o módulo de tabela verdade será utilizado inicialmente no laboratório de informática durante a aula de Lógica, com acompanhamento da professora da disciplina e de um dos autores do artigo. Os conteúdos que serão vistos nos Módulos 1, 2 e 3 já terão sido ministrados aos alunos em aula anterior.

\section{Considerações Finais e Trabalhos Futuros}

Para alcançar o objetivo do trabalho, foi necessário agregar os conceitos da Tríplice Contingência da Análise Comportamental aos elementos da gamificação. Com o estudo desses conceitos, verificou-se que os comportamentos dos usuários no modelo gamificado podem ser estimulados a partir da criação de contingências. Assim, essas contingências foram definidas por meio dos estímulos apresentados no ambiente, que foram desde a interface inicial do módulo com uma visualização direta da situação do aluno no contexto de aprendizagem e de questionamentos que embasam a resolução de atividades até à sugestão de botões de ajuda em todas atividades que necessitam da interação do usuário. Esses estímulos tiveram como intuito provocar o comportamento do usuário a partir de respostas que pudessem contribuir com sua aprendizagem em cada nível do módulo, assim os elementos de gamificação foram associados às consequências relacionadas a cada resposta dada. Além disso, a ausência de resposta ou respostas dadas depois de um tempo prolongado foram sistematizadas a partir de um conjunto de variáveis de controle para serem utilizadas posteriormente em trabalhos futuros.

Nesse sentido, como trabalhos futuros pretende-se realizar uma avaliação da utilização do módulo por acadêmicos da disciplina de Lógica, para verificar se a gamificação foi capaz de estimular os comportamentos dos usuários a partir das contingências estabelecidas, além de influenciar no desempenho e engajamento dos acadêmicos durante o processo de ensino e aprendizagem na disciplina. Outro trabalho futuro, está relacionado à implementação de uma API (Interface de Programação de Aplicação) para armazenar os dados gerados a partir da utilização do módulo e facilitar o acesso desses dados a fim de gerar informações úteis a serem apresentadas em um dashboard desenvolvido para docentes da disciplina. Dessa forma, o(a) docente poderá acompanhar, por exemplo, o progresso dos alunos durante a utilização do módulo, o tempo gasto no decorrer da resolução dos exercícios, os principais erros cometidos durante as resoluções, e até mesmo os conteúdos que mais foram solicitadas ajuda.

\section{Referências}

Bedregal, B. R. C. and Acióly, B. M. (2007). "Introdução à Lógica Clássica para a Ciência da Computação”, http://www.dimap.ufrn.br/ jmarcos/books/BA_Jul07.pdf, Julho.

Foxall, G. (2010). Interpreting consumer choice: the behavioral perspective model. New York: Routledge.

Kiesler, S. et al. (2011). Gamification in education: What, how, why bother?. Academic exchange quarterly. ResearchGate. 
VIII Congresso Brasileiro de Informática na Educação (CBIE 2019)

Anais do XXX Simpósio Brasileiro de Informática na Educação (SBIE 2019)

Klock, A. C. T., Cunha, L. F., Carvalho, M. F., Rosa, B. E., Anton, A. J and Gasparini, I. (2015). Gamification in e-Learning Systems: A Conceptual Model to Engage Students and Its Application in an Adaptive e-Learning System. In Lecture Notes In Computer Science. Springer International Publishing.

Klock, A. C. T., Gasparini, I. and Pimenta, M. S. (2016). 5W2H Framework: a guide to design, develop and evaluate the user-centered gamification. In Brazilian Symposium On Human Factors In Computer Systems (Simpósio Brasileiro sobre Fatores Humanos em Sistemas Computacionais-IHC), volume 16, page 1.

Leon, M., Ford, V., Shimizu, H., Stretz, A. H., Thompson, J., Sota, M., Twyman, J. S., and Layng, J. (2011). Comprehension by design: Teaching young learners how to comprehend what they read. In Performance Improvement. Wiley.

Mec. (2019). "Diretrizes Curriculares - Cursos de Graduação", http://portal.mec.gov.br/component/content/article?id=12991, Julho.

Medeiros, D. M. S. and Haydu, V. B. (2015). TICs e a função da gamificação na Educação em Ciências a partir de uma visão analítico-comportamental. In X Encontro Nacional de Pesquisa em Educação em Ciências. São Paulo.

Menezes, G. S., Tarachucky, L., Pellizzoni, R. C., Perassi, R. L., Gonçalves, M. M., Gomez, L. S. R., Fialho, F. A. P. (2014). Reforço e Recompensa: a Gamificação tratada sob uma abordagem behaviorista. Projetica.

Prette, G. (2011). Treino didático de análise de contingências e previsão de intervenções sobre as consequências do responder. In Perspectivas em Análise do Comportamento. Scielo.

Ribeiro, R. B., Oliveira, D. B. F., Carvalho, L. S. G. and Oliveira, E. H. T (2018). Gamificação de um Sistema de Juiz Online para Motivar Alunos em Disciplina de Programação Introdutória. In Brazilian Symposium on Computers in Education (Simpósio Brasileiro de Informática na Educação-SBIE), volume 29, page 805.

Rice, J. W. (2012). The Gamification of Learning and Instruction. In International Journal Of Gaming And Computer-mediated Simulations, pages 81-83. IGI Global.

Skinner, B. F. (1958). Teaching machines - From the experimental study of learning come devices which arrange optimal conditions for self-instruction. pages 969-97. Science.

Skinner, B. F. (1974). Ciência e comportamento humano. Tradução de João Cláudio Todorov e Rodolpho Azzi. São Paulo: EDART/Edusp. (trabalho original publicado em 1953).

Skinner, B. F. (1982). Sobre o behaviorismo. São Paulo: Cultrix.

Werbach, K. and Hunter, D. (2012). For the win: How game thinking can revolutionize your business. Wharton Digital Press.

Zanin, A., Sparremberger, A. S., Becker, T. P. and Barbosa, J. L. V. (2018). StudyPlay: Um Modelo Gamificado Para Incentivo a Realização de Atividades Extraclasse. In Brazilian Symposium on Computers in Education (Simpósio Brasileiro de Informática na Educação-SBIE), volume 29, page 1683. 